\title{
Outcome of community-acquired pneumonia: influence of age, residence status and antimicrobial treatment
}

\author{
H. Kothe*, T. Bauer ${ }^{\#}$, R. Marre ${ }^{\star}$, N. Suttorp ${ }^{+}$, T. Welte $^{\S}$, \\ K. Dalhoff* and the Competence Network for Community-Acquired \\ Pneumonia study group ${ }^{f}$
}

ABSTRACT: Community-acquired pneumonia remains a major cause of mortality in developed countries. There is much discrepancy in the literature regarding factors influencing the outcome in the elderly population.

Data were derived from a multicentre prospective study initiated by the German Competence Network for Community-Acquired Pneumonia. Patients with community-acquired pneumonia $(n=2,647 ; 1,298$ aged $<65$ yrs and 1,349 aged $\geqslant 65$ yrs) were evaluated, of whom $72.3 \%$ were hospitalised and $\mathbf{2 7 . 7 \%}$ treated in the community. Clinical history, residence status, course of disease and antimicrobial treatment were prospectively documented. Microbiological investigations included cultures and PCR of respiratory samples and blood cultures. Factors related to mortality were included in multivariate analyses.

The overall 30-day mortality was $6.3 \%$. Elderly patients exhibited a significantly higher mortality rate that was independently associated with the following: age; residence status; confusion, urea, respiratory frequency and blood pressure (CURB) score; comorbid conditions; and failure of initial therapy. Increasing age remained predictive of death in the elderly. Nursing home residents showed a four-fold increased mortality rate and an increased rate of Gram-negative bacillary infections compared with patients dwelling in the community. The CURB score and cerebrovascular disease were confirmed as independent predictors of death in this subgroup.

Age and residence status are independent risk factors for mortality after controlling for comorbid conditions and disease severity. Failure of initial therapy was the only modifiable prognostic factor.

KEYWORDS: Community-acquired pneumonia, elderly, nursing home, outcome, treatment failure

ommunity-acquired pneumonia (CAP) represents a public health problem of substantial magnitude. CAP remains the leading cause of death due to infectious diseases $[1,2]$, with an annual incidence ranging 1.6-10.6 per 1,000 adult population in Europe [3]. Prevalence and fatality rate are higher in elderly patients compared with younger populations, and will further increase given the ageing population in developed countries. In a large population-based study in the USA, the annual attack rate increased from $1.8 \%$ in patients aged $65-69$ yrs to $5 \%$ in those aged $>85$ yrs. In elderly patients, mortality has ranged $11-26 \%$ in recent studies [4-7], but may exceed $50 \%$ in nursing home residents [5]. Living in a nursing home is an important component of the recently proposed category of healthcare-associated pneumonia (HCAP) [8-10]. It is not clear to what extent the excess mortality of elderly patients and patients with HCAP reflects the higher prevalence of underlying conditions, more severe disease or an independent age-related increase in mortality risk [5, 11-13]. Apart from host-derived factors, the appropriateness of initial antimicrobial treatment has been shown to influence outcome in patient populations with severe disease, such as ventilator-associated pneumonia [14] and severe CAP [15]. However, the impact of treatment failure in nonselected CAP patients is not clear.
AFFILIATIONS

*Dept of Medicine III, University of Lübeck, Lübeck,

\#Heckeshorn Centre for Pneumology and Thoracic Surgery, HELIOS Emil von Behring Clinic,

${ }^{+}$Dept of Internal Medicine/Infectious Diseases and Pulmonary Medicine, Charité, Medical School of Berlin Humboldt University, Berlin,

"Dept of Medical Microbiology and Hygiene, University of UIm, UIm,

${ }^{\text {s}}$ Dept of Pneumology, Hanover

Medical School, Hanover, Germany. ${ }^{f}$ For full details of the Competence Network for Community-Acquired

Pneumonia see the

Acknowledgements section

CORRESPONDENCE

H. Kothe

Medizinische Klinik III

Medizinische Universität zu Lübeck Ratzeburger Allee 160

23538 Lübeck

Germany

Fax: 494515006014

E-mail: HenningKothe-tenor@

web.de

Received:

July 222007

Accepted after revision:

February 052008

\section{SUPPORT STATEMENT}

This study was supported by the Federal Ministry of Education and Research (Berlin, Germany).

STATEMENT OF INTEREST None declared. 
Rosón et al. [16] observed an association between early failure and overall mortality in hospitalised CAP patients. In contrast, in a recent study in elderly CAP patients, the necessity of changing initial therapy was not associated with an unfavourable outcome [7]. This factor may be of particular interest since, in contrast to underlying conditions, the effectiveness of initial treatment is a potentially modifiable factor.

Therefore, a prospective multicentre study was conducted in order to assess risk factors influencing CAP mortality, with a special emphasis on age, residence status, underlying conditions and antimicrobial treatment.

\section{METHODS}

\section{Setting}

The present data were derived from a multicentre prospective study initiated by the German Competence Network for Community-Acquired Pneumonia (CAPNETZ) [17]. This network has been described in detail elsewhere [18]. In brief, the network comprises 10 clinical centres throughout Germany. These centres represent hospitals and outpatient departments at all levels of healthcare provision involved in CAP research and therapy. A total of 670 private practitioners, physicians and respiratory specialists, as well as $>30$ hospitals, cooperate within CAPNETZ. The decision concerning where to treat the patient with pneumonia was left to the discretion of the attending physician. No attempt was made to implement standardised criteria or rules regarding the decision to hospitalise or choice of antibiotic therapy.

Data collection started in March 2003 and was censored for the present analysis in October 2005 (i.e. after 31 months). Consecutive nonselected patients presenting with CAP were prospectively recorded.

The study design was approved by the local ethical committees. All patients gave written informed consent and received a pseudonym from an independent third party in order to ensure data safety.

\section{Study population}

Patients presenting with a new pulmonary infiltrate on chest radiography, together with at least one symptom or sign of lower respiratory tract infection (fever, cough, purulent sputum, focal chest signs, dyspnoea and/or pleuritic pain), were eligible. Exclusion criteria were: 1) acquisition of pneumonia after hospital admission or patients re-admitted after hospital discharge of $<28$ days; 2) presence of severe immunosuppression associated with a relevant risk of opportunistic infection, i.e. chemotherapy and/or neutropenia of $<1,000$ neutrophils $\cdot \mu \mathrm{L}^{-1}$ during the last 28 days, therapy with $>20 \mathrm{mg} \cdot$ day $^{-1}$ corticosteroids for $>14$ days, known HIV infection and/or immunosuppressive therapy after organ or bone marrow transplant; 3) pneumonia as an expected terminal event of a severe chronic disabling comorbid condition; and 4) an alternative diagnosis evolving during follow-up.

\section{Data collection and evaluation}

All patients were assessed at first presentation and during follow-up according to a standardised data sheet. The following parameters were recorded: date of presentation; age; sex; alcohol habits; defined comorbid conditions; residence in nursing home; duration of symptoms; clinical symptoms on admission (body temperature, respiratory frequency, cardiac frequency, systolic and diastolic arterial blood pressure and pneumonia-associated confusion, i.e. disorientation with regard to person, place or time that is not known to be chronic); blood gas analysis $(\mathrm{pH}$, arterial oxygen and carbon dioxide tension and inspiratory oxygen fraction); chest radiography (number of lobes affected and pleural effusion); and laboratory parameters (haemoglobin, haematocrit, leukocyte count, band forms, serum creatinine, blood urea nitrogen, sodium and blood glucose). Changes of treatment were documented prospectively according to the following definitions. 1) Ineffective treatment: lack of response or worsening of clinical status requiring changes in antibiotic therapy. 2) Sequential therapy: switch from intravenous to oral therapy after documentation of clinical response. 3) De-escalation: change from broad- to narrowspectrum antibiotic therapy after identification of causative bacteria. 4) Intolerance: occurrence of adverse events possibly attributable to antibiotic therapy. 5) Resistance: isolation of causative bacteria with resistance to initial antibiotic therapy according to susceptibility testing in vitro.

After 14 days, all patients or relatives were contacted either personally or via telephone for a structured interview regarding outcome parameters, e.g. resolution of symptoms, duration of antibiotic therapy and death. This interview was repeated in order to assess 30-day mortality. Data validity and consistency checks were performed by an independent party prior to the analyses.

\section{Microbiological evaluation}

Sputum was Gram stained. Representative sputum originating from the lower respiratory tract was validated by the criteria of $>25$ granulocytes per low-power field and $<10$ epithelial cells per low-power field (total magnification of $100 \times$ ). Validated sputum, blood culture, pleural fluid, transthoracic needle aspiration, undiluted and serially diluted tracheobronchial aspirate, protected specimen brush (PSB) and bronchoalveolar lavage (BAL) fluid (BALF) samples were plated on the following media: blood-sheep agar, MacConkey agar, chocolate agar and Sabouraud agar. Undiluted PSB and BALF samples were also cultured on charcoal-yeast extract agar. Urine was tested for the presence of Streptococcus pneumoniae and Legionella antigen. Identification of microorganisms and susceptibility testing was performed according to standard methods.

\section{Diagnostic criteria}

The infectious aetiology of pneumonia was classified as probable/definite if at least one of the following criteria were met. 1) Blood cultures yielding a bacterial or fungal pathogen, in the absence of an apparent extrapulmonary focus. 2) Pleural fluid and transthoracic needle aspiration cultures yielding a bacterial pathogen. 3) Bacterial growth in cultures of tracheobronchial aspirate of $\geqslant 1 \times 10^{5}$ colony-forming units $(\mathrm{cfu}) \cdot \mathrm{mL}^{-1}$, PSB of $\geqslant 1 \times 10^{3} \mathrm{cfu} \cdot \mathrm{mL}^{-1}$ and BALF of $\geqslant 1 \times 10^{4} \mathrm{cfu} \cdot \mathrm{mL}^{-1}$. 4) A valid sputum sample ( 25 leukocytes per $10 \times$ field) yielding one or more predominant bacterial pathogens or $\geqslant 100$ pathogens per high-power field $(1,000 \times$ magnification). The following species were regarded as potential pathogens: S. pneumoniae, Haemophilus influenzae, Klebsiella pneumoniae, Staphylococcus aureus, Escherichia coli and other enterobacterial 


\begin{tabular}{|c|c|c|c|c|}
\hline \multirow{3}{*}{\multicolumn{2}{|c|}{ TABLE 1}} & clinical data & of the stuc & \multirow{3}{*}{ p-value } \\
\hline & & \multicolumn{2}{|c|}{ Age group } & \\
\hline & & $<65$ yrs & $\geqslant 65 \mathrm{yrs}$ & \\
\hline \multicolumn{2}{|l|}{ Subjects $n$} & 1298 & 1349 & \\
\hline \multicolumn{2}{|l|}{ Age yrs } & $47.2 \pm 12.7$ & $77.1 \pm 7.5$ & \\
\hline \multicolumn{2}{|c|}{ Males/females n } & $716 / 582$ & $770 / 579$ & 0.33 \\
\hline \multicolumn{2}{|c|}{ Body mass index $\mathrm{kg} \cdot \mathrm{m}^{-2}$} & $25.1 \pm 5.5$ & $25.3 \pm 4.5$ & 0.43 \\
\hline \multicolumn{2}{|c|}{ Smokers } & 44.9 & 17.8 & $<0.001$ \\
\hline \multicolumn{2}{|c|}{ Body temperature ${ }^{\circ} \mathrm{C}$} & $37.9 \pm 1.2$ & $37.7 \pm 1.1$ & $<0.001$ \\
\hline \multicolumn{2}{|c|}{ Dyspnoea } & 68.2 & 81.7 & $<0.001$ \\
\hline \multicolumn{2}{|c|}{ Purulent sputum } & 53.3 & 62.3 & $<0.001$ \\
\hline \multicolumn{2}{|l|}{ Cough } & 87.0 & 84.0 & 0.29 \\
\hline \multicolumn{2}{|c|}{ Pleuritic pain } & 49.0 & 28.5 & $<0.001$ \\
\hline \multicolumn{2}{|c|}{ Pleuritic effusion } & 12.6 & 18.3 & $<0.001$ \\
\hline \multicolumn{2}{|c|}{ Confusion } & 5.2 & 16.4 & $<0.001$ \\
\hline \multicolumn{2}{|c|}{ BUN mM } & $5.7 \pm 4.7$ & $9.2 \pm 6.3$ & $<0.001$ \\
\hline \multicolumn{2}{|c|}{$\begin{array}{l}\text { Respiratory frequency } \\
\text { breaths } \cdot \mathrm{min}^{-1}\end{array}$} & $19.8 \pm 6.5$ & $20.8 \pm 6.6$ & $<0.001$ \\
\hline \multicolumn{5}{|c|}{ Blood pressure mmHg } \\
\hline \multicolumn{2}{|c|}{ Systolic } & $123.3 \pm 19.0$ & $134.6 \pm 24.4$ & $<0.01$ \\
\hline \multicolumn{2}{|l|}{ Diastolic } & $74.7 \pm 11.8$ & $75.9 \pm 13.6$ & $<0.001$ \\
\hline \multicolumn{2}{|l|}{ Blood pH } & $7.45 \pm 0.07$ & $7.44 \pm 0.06$ & $<0.01$ \\
\hline \multicolumn{2}{|c|}{$\mathrm{Pa}, \mathrm{O}_{2} \mathrm{mmHg}$} & $67.2 \pm 17.3$ & $65.1 \pm 16.8$ & $<0.05$ \\
\hline \multicolumn{2}{|c|}{$\mathrm{Pa}, \mathrm{CO}_{2} \mathrm{mmHg}$} & $35.4 \pm 8.2$ & $36.9 \pm 8.7$ & $<0.05$ \\
\hline \multicolumn{2}{|c|}{$\mathrm{Sa}_{\mathrm{a}} \mathrm{O}_{2} \%$} & $92.6 \pm 6.1$ & $91.4 \pm 5.7$ & $<0.01$ \\
\hline \multicolumn{2}{|c|}{ Leukocytes cells $\cdot \mathrm{nL}^{-1}$} & $12.6 \pm 6.2$ & $13.3 \pm 6.1$ & $<0.01$ \\
\hline \multicolumn{2}{|c|}{ C-reactive protein $\mathrm{mg} \cdot \mathrm{L}^{-1}$} & $137.4 \pm 127.9$ & $139.6 \pm 118.6$ & 0.68 \\
\hline \multicolumn{2}{|c|}{ Glucose $\mathrm{mM}$} & $6.6 \pm 2.9$ & $8.1 \pm 3.8$ & $<0.001$ \\
\hline
\end{tabular}

Data are presented as mean \pm SD or \%, unless otherwise indicated. BUN: blood urea nitrogen; $\mathrm{Pa}_{1} \mathrm{O}_{2}$ : arterial oxygen tension; $\mathrm{Pa}_{2} \mathrm{CO}_{2}$ : arterial carbon dioxide tension; $\mathrm{Sa}_{1} \mathrm{O}_{2}$ : arterial oxygen saturation. $1 \mathrm{mmHg}=0.133 \mathrm{kPa}$.

species, Pseudomonas aeruginosa, Moraxella catarrhalis and Stenotrophomonas maltophilia. 5) Chlamydia pneumoniae: immunoglobulin $M \geqslant 1: 32$ and/or PCR-positive in at least two different laboratories. 6) Legionella spp.: bacterial growth in respiratory secretions, lung tissue or pleural fluid, or detection of urinary antigen or Legionella-specific DNA by PCR. 7) Mycoplasma pneumoniae: PCR-positive. 8) Positive urinary antigen for S. pneumoniae. 9) PCR-positive for influenza virus A and $\mathrm{B}$, respiratory syncytial virus, adenovirus or enterovirus.

\section{Statistical analysis}

First, the demographic and clinical data of the two age groups $(<65 \mathrm{yrs}$ and $\geqslant 65 \mathrm{yrs})$ of CAP patients were compared. Secondly, risk factors for 30-day mortality were evaluated by univariate and multivariate analysis of the whole patient population and in the subgroup of elderly patients.

Results are presented as frequency and percentage or mean $\pm S D$, unless otherwise indicated. The Chi-squared test was used to compare proportions, and Fisher's exact test was performed when appropriate. Continuous variables were compared by means of an unpaired t-test. The $95 \%$ confidence intervals (CIs) are reported for all comparisons, and exact

\begin{tabular}{|c|c|c|c|}
\hline & \multicolumn{2}{|c|}{ Age group } & \multirow[t]{2}{*}{ p-value } \\
\hline & $<65$ yrs & $\geqslant 65$ yrs & \\
\hline Patients n & 1298 & 1349 & \\
\hline Pathogens detected $n$ & 271 & 268 & \\
\hline Streptococcus pneumoniae \% & 42.1 & 43.3 & 0.85 \\
\hline Gram-negative bacilli \% & 3.7 & 7.1 & 0.17 \\
\hline Staphylococcus aureus \% & 1.5 & 2.2 & 0.74 \\
\hline Haemophilus influenzae \% & 4.8 & 3.4 & 0.53 \\
\hline Chlamydia pneumoniae \% & 1.1 & 0 & 0.26 \\
\hline Mycoplasma pneumoniae \% & 14.0 & 0.7 & 0.0005 \\
\hline Legionella spp. \% & 16.6 & 17.5 & 0.87 \\
\hline Respiratory syncytial virus \% & 1.8 & 3.7 & 0.29 \\
\hline Influenza virus A \% & 5.9 & 14.9 & 0.001 \\
\hline
\end{tabular}

intervals for single proportions were estimated according to NeWCOMBE [19]. Effects on mortality were assessed by stepwise forward logistic regression analyses (largest $p$-value for entering variables 0.05 ; smallest $p$-value for removing variables 0.10) for the following variables: age, comorbid conditions, residence status, failure of initial antibiotic treatment, sequential therapy and risk class assignment (confusion, urea, respiratory frequency and blood pressure (CURB) score). The standardised expected $\beta$ coefficient, 95\% CI and level of significance are reported. All tests were explorative and twosided and the significance level was set at 5\%.

\section{RESULTS}

\section{Patient characteristics}

Overall, 3,574 patients were contacted through the network during the study period, of whom 2,647 gave informed consent, showed no other evolving diagnoses during followup and were included in the analysis. The proportions of hospitalised patients and outpatients were 74.8 and $25.2 \%$, respectively. Table 1 displays the demographic and clinical data of patients aged $<65$ yrs and $\geqslant 65$ yrs. No significant differences were found between the subgroups regarding sex and body mass index. On clinical examination, elderly patients revealed a higher rate of dyspnoea, purulent sputum and pleuritic effusion, whereas younger patients showed a higher incidence of pleuritic pain. Regarding the laboratory parameters, major differences included elevated levels of blood urea nitrogen and glucose in elderly patients.

\section{Microbiological patterns}

Table 2 shows the distribution of respiratory pathogens in the two age groups. The availability of valid respiratory samples was significantly higher in the younger population than in the elderly, e.g. sputum samples suitable for culture were recovered in 56.5 versus $43.1 \%(\mathrm{p}<0.001)$, BAL/PSB was performed in 5.6 versus $2.9 \%(\mathrm{p}=0.001)$ and thoracocentesis in 1.1 versus $0.7 \% \quad(p=0.05)$, respectively. There was no difference between age groups concerning recovery of bronchial secretions (4.9 versus $5.6 \%$; $\mathrm{p}=0.44$ ). Overall, a definite 


\begin{tabular}{|c|c|c|c|c|}
\hline \multirow[t]{3}{*}{ TABLE 3} & \multicolumn{4}{|c|}{$\begin{array}{l}\text { Comorbid conditions, residence status and } \\
\text { treatment changes }\end{array}$} \\
\hline & & \multicolumn{2}{|c|}{ Age group } & \multirow[t]{2}{*}{ p-value } \\
\hline & & $<65$ years & $\geqslant 65$ years & \\
\hline Subjects n & & 1298 & 1349 & \\
\hline CURB score & & $0.55 \pm 0.73$ & $1.03 \pm 0.89$ & $<0.001$ \\
\hline \multicolumn{5}{|c|}{ Comorbid condition } \\
\hline Chronic pu & nonary disease & 30.0 & 42.6 & $<0.001$ \\
\hline Chronic he & t disease & 12.8 & 47.2 & $<0.001$ \\
\hline Congestive & neart failure & 6.4 & 37.9 & $<0.001$ \\
\hline Chronic live & disease & 3.9 & 3.3 & 0.46 \\
\hline Chronic kic & ey failure & 2.9 & 13.3 & $<0.001$ \\
\hline Cerebrovas & ular disease & 4.1 & 22.3 & $<0.001$ \\
\hline Other neur & ogical disorder & 6.6 & 10.1 & 0.001 \\
\hline Diabetes $m$ & llitus & 8.3 & 28.1 & $<0.001$ \\
\hline Nursing hon & & 3.3 & 15.2 & $<0.001$ \\
\hline 30-day mort & & 2.2 & 10.3 & $<0.001$ \\
\hline \multicolumn{5}{|c|}{ Change of antibiotic treatment } \\
\hline Overall & & 25.4 & 32.6 & $<0.001$ \\
\hline Ineffectiven & & 10.9 & 11.6 & 0.58 \\
\hline Sequential & nerapy & 8.2 & 13.1 & $<0.001$ \\
\hline De-escalati & & 3.8 & 4.8 & 0.13 \\
\hline Intolerance & & 1.3 & 1.2 & 0.86 \\
\hline Resistance & & 0.7 & 1.7 & 0.03 \\
\hline
\end{tabular}

Data are presented as mean \pm SD or $\%$, unless otherwise stated. CURB: confusion, urea, respiratory frequency and blood pressure.

microbial aetiology could be determined in 539 (20.4\%) cases. Most pathogens were equally distributed across the age groups. A significantly increased rate of influenza infection was found in the elderly, whereas infections with $M$. pneumoniae occurred significantly more frequently in the younger population group.

\section{Comorbid conditions and residence status}

As displayed in table 3, elderly patients showed a significantly higher incidence of severe comorbid conditions. In addition, the mean CURB score was almost twice as high in the elderly population, indicating more severe disease.

\section{Outcome}

The overall 30-day mortality was $6.3 \%$, and was significantly higher among elderly patients (10.3\%) than in the younger age group $(2.2 \% ; \mathrm{p}<0.001)$. Risk factors associated with mortality were first assessed in the whole study group. As shown in table 4, the CURB score, age, nursing home residence and several comorbid conditions were associated with 30-day mortality. Moreover, change of antibiotic therapy due to treatment failure was a significant risk factor. In contrast, sequential therapy was associated with a better outcome. Table 5 displays the results of logistic regression analysis of the variables included in the multivariate model to describe independent prognostic factors. The CURB score, age of $\geqslant 65 \mathrm{yrs}$, nursing home residence, congestive heart failure, cerebrovascular disease and chronic liver disease remained

\begin{tabular}{|c|c|c|c|}
\hline \multirow[t]{2}{*}{ TABLE 4} & \multicolumn{3}{|c|}{$\begin{array}{l}\text { Univariate analysis of risk factors for 30-day } \\
\text { mortality in community-acquired pneumonia } \\
\text { patients }\end{array}$} \\
\hline & & OR $(95 \% \mathrm{Cl})$ & p-value \\
\hline \multicolumn{2}{|c|}{ Age $<65 / \geqslant 65$ yrs } & $5.03(3.34-7.56)$ & $<0.001$ \\
\hline \multicolumn{4}{|c|}{ Comorbid condition } \\
\hline \multicolumn{2}{|c|}{ Chronic pulmonary disease } & $1.104(0.80-1.53)$ & 0.560 \\
\hline \multicolumn{2}{|c|}{ Chronic heart disease } & $2.76(2.01-3.78)$ & $<0.001$ \\
\hline \multicolumn{2}{|c|}{ Congestive heart failure } & $4.91(3.56-6.78)$ & $<0.001$ \\
\hline \multicolumn{2}{|c|}{ Cerebrovascular disease } & $5.91(4.25-8.22)$ & $<0.001$ \\
\hline \multicolumn{2}{|c|}{ Other neurological disorder } & $3.86(2.61-5.69)$ & $<0.001$ \\
\hline \multicolumn{2}{|c|}{ Chronic liver disease } & $2.98(1.67-5.29)$ & 0.001 \\
\hline \multicolumn{2}{|c|}{ Chronic kidney failure } & $4.22(2.86-6.22)$ & $<0.001$ \\
\hline \multicolumn{2}{|c|}{ Diabetes mellitus } & $2.55(1.83-3.57)$ & $<0.001$ \\
\hline \multicolumn{2}{|c|}{ Nursing home } & $8.00(5.66-11.30)$ & $<0.001$ \\
\hline \multicolumn{2}{|c|}{ CURB score ${ }^{\#}$} & $2.60(2.10-3.20)$ & $<0.001$ \\
\hline \multicolumn{4}{|c|}{ Change of antibiotic treatment } \\
\hline \multicolumn{2}{|c|}{ Overall } & $1.30(0.90-1.83)$ & 0.186 \\
\hline \multicolumn{2}{|c|}{ Ineffectiveness } & $2.24(1.50-3.34)$ & 0.001 \\
\hline \multicolumn{2}{|c|}{ Sequential therapy } & $0.46(0.24-0.94)$ & 0.026 \\
\hline \multicolumn{2}{|c|}{ De-escalation } & $0.40(0.13-1.27)$ & 0.159 \\
\hline \multicolumn{2}{|c|}{ Intolerance } & $1.52(0.46-5.02)$ & 0.457 \\
\hline \multicolumn{2}{|l|}{ Resistance } & $0.94(0.93-0.95)$ & 0.258 \\
\hline
\end{tabular}

OR: odds ratio; $\mathrm{Cl}$ : confidence interval; CURB: confusion, urea, respiratory frequency and blood pressure. ${ }^{*}$ : univariate analysis performed as logistic regression; OR and 95\% $\mathrm{Cl}$ shown are per step.

significant risk factors for death. Treatment failure was confirmed as an independent risk factor during the course of disease.

\section{Prognostic factors in the elderly}

Factors related to death were subsequently analysed separately in the subgroup of elderly patients (those aged $\geqslant 65 \mathrm{yrs}$ ). Univariate analysis revealed similar results to the total CAP population (data not shown). In the multivariate model (table 6), CURB score, residence status, cerebrovascular disease, chronic liver disease and treatment failure were predictive of death. In addition, increasing age remained an independent risk factor in this subgroup. The prognostic impact of advanced age was also illustrated when alternative age limits $(\geqslant 75$ yrs $(n=766)$ and $\geqslant 85$ yrs $(n=200))$ were applied in the elderly population; most risk factors were distributed with increasing frequency in consecutive age cohorts (table E1 in the supplementary material).

\section{Nursing home-acquired pneumonia}

The present exclusion criteria (e.g. prior hospitalisation and immunosuppressive chemotherapy) meant that patients with HCAP were only partially included in the study. Therefore, it was decided to focus on patients residing in nursing homes or long-term care facilities as an important and well defined subgroup [20] of HCAP. Of the elderly patients, $15.2 \%$ belonged to this category and were evaluated separately. This population was characterised by a more than four-fold increased mortality rate compared with elderly patients dwelling in the community 


\begin{tabular}{|c|c|c|c|}
\hline \multirow[t]{2}{*}{ TABLE 5} & \multicolumn{3}{|c|}{$\begin{array}{l}\text { Multivariate analysis of risk factors for } 30 \text {-day } \\
\text { mortality in community-acquired pneumonia } \\
\text { patients }\end{array}$} \\
\hline & & $\beta(95 \% \mathrm{Cl})$ & p-value \\
\hline \multicolumn{2}{|c|}{ Age $<65 / \geqslant 65$ yrs } & $1.84(1.06-3.18)$ & 0.030 \\
\hline \multicolumn{4}{|c|}{ Comorbid condition } \\
\hline \multicolumn{2}{|c|}{ Congestive heart failure } & $1.85(1.18-2.92)$ & 0.007 \\
\hline \multicolumn{2}{|c|}{ Cerebrovascular disease } & $1.84(1.13-3.00)$ & 0.014 \\
\hline \multicolumn{2}{|c|}{ Chronic liver disease } & $4.10(1.98-8.49)$ & $<0.001$ \\
\hline \multicolumn{2}{|c|}{ Nursing home } & $2.95(1.80-4.83)$ & $<0.001$ \\
\hline \multicolumn{2}{|c|}{ CURB score } & $2.13(1.69-2.69)$ & $<0.001$ \\
\hline \multicolumn{4}{|c|}{ Change of antibiotic treatment } \\
\hline \multicolumn{2}{|c|}{ Ineffectiveness } & $1.74(1.07-2.83)$ & 0.027 \\
\hline \multicolumn{2}{|c|}{ Sequential therapy } & $0.26(0.10-0.62)$ & 0.003 \\
\hline \multicolumn{4}{|c|}{ Comorbid condition } \\
\hline \multicolumn{2}{|c|}{ Chronic pulmonary disease } & & 0.756 \\
\hline \multicolumn{2}{|c|}{ Chronic heart disease } & & 0.523 \\
\hline \multicolumn{2}{|c|}{ Chronic kidney failure } & & 0.622 \\
\hline \multicolumn{2}{|c|}{ Diabetes mellitus } & & 0.849 \\
\hline \multicolumn{2}{|c|}{ Other neurological disorder } & & 0.062 \\
\hline \multicolumn{4}{|c|}{ Change of antibiotic treatment } \\
\hline \multicolumn{2}{|c|}{ Overall } & & 0.106 \\
\hline \multicolumn{2}{|c|}{ De-escalation } & & 0.080 \\
\hline \multicolumn{2}{|c|}{ Intolerance } & & 0.810 \\
\hline \multicolumn{2}{|l|}{ Resistance } & & 0.080 \\
\hline
\end{tabular}

Cl: confidence interval; CURB: confusion, urea, respiratory frequency and blood pressure.

(28.8 versus $6.9 \%$ ) and a significantly increased CURB score $(1.52 \pm 1.01$ versus $0.93 \pm 0.83)$. Cardiovascular, neurological and renal comorbid conditions occurred significantly more frequently in this subgroup (table 7). Multivariate analysis confirmed the CURB score ( $\beta$ 1.69, 95\% CI (1.12-2.55); $\mathrm{p}=0.013)$ and cerebrovascular disease (2.88 (1.14-7.30); $\mathrm{p}=0.026)$ as independent prognostic factors in this group. Interestingly, a higher incidence of Gram-negative bacillary infections was observed than in elderly patients living in the community (18.8 versus $5.5 \%$ of cases with positive microbiological findings; $\mathrm{p}=0.02$ ), whereas $S$. aureus (2.3 versus $1.0 \%$; nonsignificant) and $P$. aeruginosa (1.0 versus $0.3 \%$; nonsignificant) were rarely recovered in either group. In order to evaluate whether or not the inclusion of nursing home-acquired pneumonia (NHAP) influenced the findings in the total CAP population, data were analysed with and without this subgroup. Uni- and multivariate analysis of risk factors for mortality showed very similar results after exclusion of patients with NHAP (tables E2 and E3 in the supplementary material).

\section{DISCUSSION}

The major findings of the present study are: 1) 30-day mortality in CAP patients was independently associated with an age of $\geqslant 65$ yrs and residence status, even when comorbid conditions and the CURB score were taken into account; and 2) failure of initial antimicrobial treatment was independently associated with a higher mortality rate, whereas sequential therapy was related to a favourable outcome.

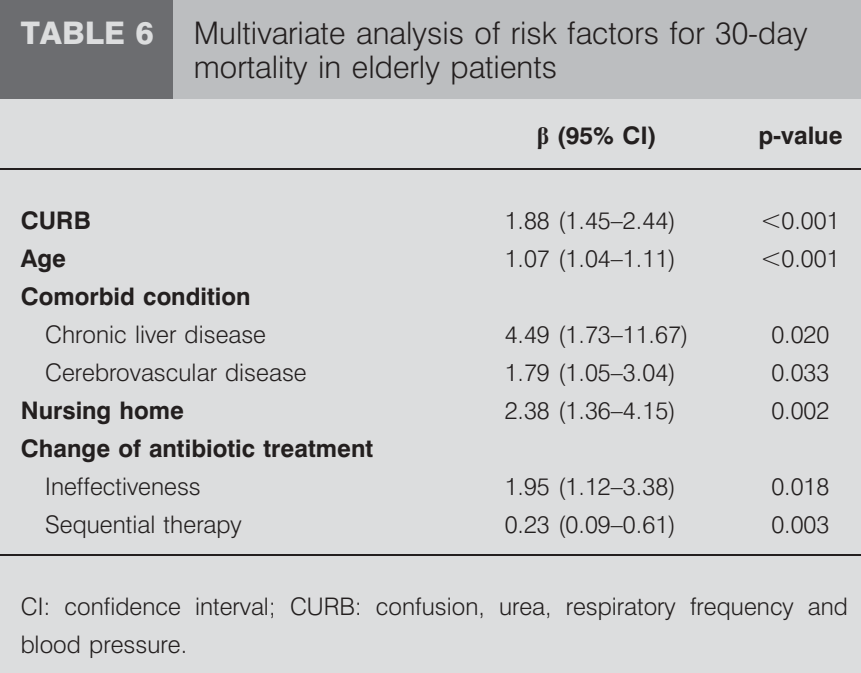

CAP is a common condition in the elderly population, with a highly variable prognosis, ranging from rapid recovery to lifethreatening complications and death. The present CAP population is comparable to recently described cohorts from the USA and Spain $[7,11]$, with an increased mortality rate of $10.3 \%$ and an increased frequency of comorbid conditions in the elderly. Age remained an independent risk factor for death in multivariate analysis after controlling for comorbid conditions, severity of disease, residence status and treatmentrelated factors. These findings were reproducible when the age limit for elderly patients was shifted to $\geqslant 75$ yrs or $\geqslant 85$ yrs. Possible explanations include changes in functional status not controlled for in the present study [21] and the age-related decline in immune function [22] that may also adversely affect the outcome of pneumonia. The findings are in line with prior studies describing a prognostic impact of age irrespective of time of death (early versus late mortality) or cause of death (pneumonia-related versus pneumonia-unrelated) [21].

Risk scoring is, therefore, even more important in the elderly population. Established scoring systems, such as the pneumonia severity index, are complex and may not be widely used in clinical practice. The CURB score includes blood urea nitrogen and is, therefore, not immediately available. Recent data indicate that CURB can be safely substituted by confusion, respiratory frequency and blood pressure in those aged $\geqslant 65$ yrs (CRB-65) [23]. This is, however, not advisable in geriatric patients, since all of them fulfil at least the criterion of $\geqslant 65$ yrs. The present study, therefore, looked for additional outcome-relevant factors in CAP patients, with a special emphasis on age and age-related factors.

Among the numerous underlying conditions tested, cerebrovascular disease and chronic liver disease were identified as independent risk factors for mortality in the elderly patient population. Cerebrovascular disease has not previously been identified as a prognostic indicator in elderly patients [5, 1113]. This finding may be relevant due to the high prevalence of this comorbid condition in the elderly $(22.3 \%$ in $\geqslant 65$-yr-old CAP patients and $63.8 \%$ in the nursing home-resident subgroup in the present study). Chronic liver disease has previously been identified as an independent risk factor for 


\begin{tabular}{|c|c|c|c|c|}
\hline \multirow{3}{*}{\multicolumn{2}{|c|}{ TABLE 7}} & ence status & n outcome & \multirow{3}{*}{$\mathrm{p}$-value } \\
\hline & & \multicolumn{2}{|c|}{ Residence status } & \\
\hline & & Nursing home & Home & \\
\hline Subjects $\mathrm{n}$ & & 205 & 1144 & \\
\hline Age yrs & & $82.3 \pm 7.9$ & $76.1 \pm 7.0$ & $<0.001$ \\
\hline CURB score & & $1.52 \pm 1.01$ & $0.93 \pm 0.83$ & $<0.001$ \\
\hline \multicolumn{5}{|c|}{ Comorbid condition } \\
\hline Chronic pul & Ionary disease & 31.7 & 44.5 & 0.001 \\
\hline Chronic hea & disease & 53.5 & 46.1 & 0.055 \\
\hline Congestive & eart failure & 57.4 & 34.4 & $<0.001$ \\
\hline Chronic live & disease & 3.0 & 3.3 & 1.000 \\
\hline Chronic kid & ey failure & 23.1 & 11.6 & $<0.001$ \\
\hline Cerebrovas & ular disease & 63.8 & 15.0 & $<0.001$ \\
\hline Other neuro & gical disorder & 28.9 & 6.8 & $<0.001$ \\
\hline Diabetes $\mathrm{m}$ & litus & 36.0 & 26.5 & 0.004 \\
\hline 30-day morta & & 28.8 & 6.9 & $<0.001$ \\
\hline \multicolumn{5}{|c|}{ Change of antibiotic treatment } \\
\hline Overall & & 39.7 & 31.4 & 0.029 \\
\hline Ineffectiven & & 14.1 & 11.2 & 0.233 \\
\hline Sequential & erapy & 15.6 & 12.7 & 0.257 \\
\hline De-escalatic & & 5.5 & 4.9 & 0.597 \\
\hline Intolerance & & 1.0 & 1.2 & 1.000 \\
\hline Resistance & & 2.0 & 1.6 & 0.560 \\
\hline
\end{tabular}

Data are presented as mean \pm SD or $\%$, unless otherwise stated. CURB: confusion, urea, respiratory frequency and blood pressure.

mortality [11, 13], bacteraemia [24] and treatment failure [25] in CAP patients.

Although chronic obstructive pulmonary disease (COPD) is one of the most frequent risk factors for pneumonia and some high-risk aetiologies [26, 27], chronic pulmonary disorders were not associated with increased mortality due to CAP in the present study. Correspondingly, the pneumonia severity index does not include COPD among the comorbid conditions increasing mortality risk [28]. The present study confirms these findings for the elderly population. However, this may not apply to the subgroup with severe COPD; in a recent study on CAP patients admitted to the intensive care unit, COPD was independently associated with mortality [29]. The reasons for the generally benign course of CAP in COPD patients are not clear. Glucocorticoid treatment could exert beneficial effects in COPD patients with CAP [25], but the interaction between COPD, acute steroid administration and CAP remains to be elucidated.

Overall, $15 \%$ of the present elderly patients were nursing home residents, which is a relatively high proportion compared with recent studies on CAP in this age group [7, 11]. Acquiring pneumonia in a nursing home showed one of the highest associations with mortality, and remained an independent prognostic factor in the subgroup of patients aged $\geqslant 65 \mathrm{yrs}$, with a more than four-fold increased death rate compared with elderly patients dwelling in the community. This finding confirms data showing a significantly increased mortality risk in HCAP compared with CAP populations [8-10]. Disparate findings regarding the impact of nursing home residence on outcome in previous studies $[5,7,11]$ may reflect differences in healthcare systems and long-term care facilities. A large study on $\geqslant 65$-yr-old persons found an independently increased mortality risk in pneumonia patients with cognitive impairment and limitations in daily activity [30].

NHAP is an important subgroup of HCAP, accounting for 25$50 \%$ of HCAP cases in recent studies [8-10]. Since the more comprehensive concept of HCAP was published after initiation of the present study, patients in other HCAP categories, such as prior hospital admission or immunosuppressive chemotherapy, were not available for analysis. Interestingly, the present study showed a higher rate of infection with Gram-negative bacilli in patients with NHAP, corroborating studies on the aetiology of HCAP in this respect $[10,31]$. In contrast, data on elevated rates of staphylococcal and Pseudomonas infection [8, 10] could not be reproduced in the present study or by other authors $[9,32]$. This may be explained by different epidemiological patterns and the fact that major risk factors for Pseudomonas infection, such as prior hospitalisation, were excluded in the present population, in contrast to studies with higher incidences of this pathogen [8]. Thus, coverage against Pseudomonas and methicillin-resistant $S$. aureus may not be routinely needed in this patient group.

Another important finding of the present study is that failure of initial treatment is an independent risk factor for mortality in nonselected CAP patients. Previous studies on the impact of initial treatment on outcome have focused on critically ill patients [14, 15, 33] and patients with bacteraemia [34]. In a recent study of elderly CAP patients, modification of treatment due to a combination of causes (inefficiency, detection of uncovered microorganisms or intolerance) had no influence on outcome [7], which may be due to the different reasons underlying the decision to change. The availability of prospective data on the reasons for treatment change permitted consistent definition of treatment failures across the study population. The failure rate of $11.1 \%$ is within the range of previous investigations of CAP in hospitalised patients [34, 35]. The association with death was independent after adjustment for age, comorbid conditions, residence status and disease severity, as measured by the CURB score. This suggests that treatment-related factors, such as timeliness of antibiotic administration and choice of drug, may have an influence on prognosis. Indeed, some data in the literature suggest that treatment conforming to guidelines is associated with a better outcome [36, 37]. In a recent study on hospitalised CAP patients, Rosón et al. [16] focused on the causes of early failure, and found that a proportion of these cases were associated with discordant therapy, which may be preventable by a rational application of treatment guidelines. Early failures showed a significantly higher overall mortality.

Interestingly, sequential treatment was associated with decreased mortality in the present study, suggesting that the ability to institute sequential treatment represents an indicator of favourable outcome. This finding is in line with the experience that such treatment is feasible in most patients with nonsevere CAP [38-40], and suggests that it can be safely administered irrespective of age and other risk factors. 
Some limitations of the present study merit consideration. First, the present results may not be directly transferable to other countries, since the rate of drug-resistant pathogens, such as penicillin-resistant S. pneumoniae, is markedly lower in Germany than in many other countries. Secondly, the aetiology of CAP could be identified in only a minority of patients. The pathogen detection rate of $20 \%$ was in the same range as in some recent studies [41], but lower than in others [7, 34]. This may be due to the criteria for acceptance of diagnostic materials, e.g. high-quality standards for acceptance of sputum for culture and exclusion of serology, and to the study design, with multiple ambulatory and clinical sites. Therefore, it was decided not to include aetiology in the present outcome analysis. Thirdly, the choice of antimicrobial treatment was left to the discretion of the physicians in charge. Therefore, using the present data, it was not possible to determine how many treatment failures were potentially avoidable by use of a predefined clinical pathway. However, all CAPNETZ investigators had access to current national and international treatment guidelines, and regular training activities were instituted at the local clinical centres during the study period.

In conclusion, the risk factors described in the present study may help in the further identification of community-acquired pneumonia patients at increased risk of mortality who require special attention during the course of the disease. Age and residence status seem to be of particular importance regarding demographic changes in Western countries. In addition, the present results suggest that failure of initial treatment has an independent negative prognostic impact in nonselected community-acquired pneumonia patients. Since this is a potentially modifiable factor, further studies should evaluate treatment optimisation strategies with a special focus on patient groups with increased mortality risk.

\section{ACKNOWLEDGEMENTS}

The Competence Network for Community-Acquired Pneumonia (CAPNETZ) is a multidisciplinary approach to the better understanding and treatment of patients with community-acquired pneumonia. This network has only been made possible by the contribution of many investigators. The present authors are especially indebted to the work of the investigators in the local clinical centres, who established and maintained contact with all practitioners, physicians and respiratory specialists cooperating within the network (all in Germany): H. Lode and M. SchmidtIoanas (Heckeshorn Centre for Pneumology and Thoracic Surgery, HELIOS Emil von Behring Clinic, Berlin); A. Kuhnke and M. Becker (Dept of Internal Medicine/Infectious Diseases and Pulmonary Medicine, Charité, Medical School of Berlin Humboldt University, Berlin); B. Schlosser and E. Marchel (Berufsgenossenschaftliches Universitätsklinikum Bergmannsheil, Bochum); M. Pletz (Dept of Pneumology, Hanover Medical School, Hanover); C. Beiring and N. Schuebel (Dept of Medicine III, University of Lübeck, Lübeck); J. Lorenz and I. Huntemann (Lüdenscheid Medical Centre, Lüdenscheid); T. Klante (Dept of Pneumology, University of Magdeburg, Magdeburg); T. Schaberg and K. Voigt (Pneumology Centre, Diakoniekrankenhaus, Rotenburg an der Wümme); M. Hetzel and P.M. Lepper (Dept of Medicine II, University of Ulm, Ulm); and B. Jany and U. Ziegler (Missionsärztliche Klinik, Würzburg). In addition, the authors would like to acknowledge the work of the CAPNETZ central computing unit, including M. Weber, T. Illmann and M. Wallner, the CAPNETZ central service unit, including $\mathrm{H}$. von Baum, S. Gonschior and K. Richter as well as B. Schweiger (Robert Koch Institute, Berlin).

It is also the responsibility and pleasure of the present authors to express their appreciation to all of the clinical physicians and physicians in private practice who saw and identified patients with community-acquired pneumonia for their work dedicated to the CAPNETZ.

\section{REFERENCES}

1 Niederman MS, McCombs JS, Unger AN, Kumar A, Popovian R. The cost of treating community-acquired pneumonia. Clin Ther 1998; 20: 820-837.

2 Garibaldi RA. Epidemiology of community-acquired respiratory tract infections in adults. Incidence, etiology, and impact. Am J Med 1985; 78: 32-37.

3 European Respiratory Society/European Lung Foundation. Major respiratory diseases: pneumonia. In: Loddenkemper R, Gibson GJ, Sibille Y, eds. European Lung White Book. The First Comprehensive Survey on Respiratory Health in Europe. Sheffield, European Respiratory Society Journals, 2003; pp. 55-64.

4 Gleason PP, Meehan TP, Fine JM, Galusha DH, Fine MJ. Associations between initial antimicrobial therapy and medical outcomes for hospitalized elderly patients with pneumonia. Arch Intern Med 1999; 159: 2562-2572.

5 Lim WS, Macfarlane JT. A prospective comparison of nursing home acquired pneumonia with community acquired pneumonia. Eur Respir J 2001; 18: 362-368.

6 Riquelme R, Torres A, el-Ebiary $\mathrm{M}$, et al. Communityacquired pneumonia in the elderly. Clinical and nutritional aspects. Am J Respir Crit Care Med 1997; 156: 1908-1914.

7 Zalacain R, Torres A, Celis R, et al. Community-acquired pneumonia in the elderly: Spanish multicentre study. Eur Respir J 2003; 21: 294-302.

8 Micek ST, Kollef KE, Reichley RM, Roubinian N, Kollef MH. Health care-associated pneumonia and community-acquired pneumonia: a single-center experience. Antimicrob Agents Chemother 2007; 51: 3568-3573.

9 Carratalà J, Mykietiuk A, Fernández-Sabé N, et al. Health care-associated pneumonia requiring hospital admission: epidemiology, antibiotic therapy, and clinical outcomes. Arch Intern Med 2007; 167: 1393-1399.

10 Kollef MH, Shorr A, Tabak YP, Gupta V, Liu LZ, Johannes RS. Epidemiology and outcomes of health-careassociated pneumonia: results from a large US database of culture-positive pneumonia. Chest 2005; 128: 3854-3862.

11 Kaplan V, Angus DC, Griffin MF, Clermont G, Scott Watson R, Linde-Zwirble WT. Hospitalized communityacquired pneumonia in the elderly: age- and sex-related patterns of care and outcome in the United States. Am J Respir Crit Care Med 2002; 165: 766-772.

12 Marrie TJ, Durant H, Yates L. Community-acquired pneumonia requiring hospitalization: 5-year prospective study. Rev Infect Dis 1989; 11: 586-599.

13 Mortensen EM, Coley CM, Singer DE, et al. Causes of death for patients with community-acquired pneumonia: results 
from the Pneumonia Patient Outcomes Research Team cohort study. Arch Intern Med 2002; 162: 1059-1064.

14 Luna CM, Aruj P, Niederman MS, et al. Appropriateness and delay to initiate therapy in ventilator-associated pneumonia. Eur Respir J 2006; 27: 158-164.

15 Rello J, Bodi M, Mariscal D, et al. Microbiological testing and outcome of patients with severe community-acquired pneumonia. Chest 2003; 123: 174-180.

16 Rosón B, Carratalà J, Fernández-Sabé N, Tubau F, Manresa F, Gudiol F. Causes and factors associated with early failure in hospitalized patients with communityacquired pneumonia. Arch Intern Med 2004; 164: 502-508.

17 Competence Network for Community-Acquired Pneumonia. Kompetenznetz Ambulant Erworbene Pneumonie. [Competence Network for Community-Acquired Pneumonia.] www.capnetz.de Date last accessed: May 12, 2008.

18 Welte T, Suttorp N, Marre R. CAPNETZ-communityacquired pneumonia competence network. Infection 2004; 32: 234-238.

19 Newcombe RG. Improved confidence intervals for the difference between binomial proportions based on paired data. Stat Med 1998; 17: 2635-2650.

20 Fujitani S, Yu VL. A new category-healthcare-associated pneumonia: a good idea, but problems with its execution. Eur J Clin Microbiol Infect Dis 2006; 25: 627-631.

21 Marrie TJ, Wu L. Factors influencing in-hospital mortality in community-acquired pneumonia: a prospective study of patients not initially admitted to the ICU. Chest 2005; 127 : 1260-1270.

22 Meyer KC. Aging. Proc Am Thorac Soc 2005; 2: 433-439.

23 Bauer TT, Ewig S, Marre R, Suttorp N, Welte T, CAPNETZ study group. CRB-65 predicts death from communityacquired pneumonia. J Intern Med 2006; 260: 93-101.

24 Metersky ML, Ma A, Bratzler DW, Houck PM. Predicting bacteremia in patients with community-acquired pneumonia. Am J Respir Crit Care Med 2004; 169: 342-347.

25 Menéndez R, Torres A, Zalacain R, et al. Risk factors of treatment failure in community acquired pneumonia: implications for disease outcome. Thorax 2004; 59: 960-965.

26 Arancibia F, Bauer TT, Ewig S, et al. Community-acquired pneumonia due to Gram-negative bacteria and Pseudomonas aeruginosa: incidence, risk, and prognosis. Arch Intern Med 2002; 162: 1849-1858.

27 Torres A, Dorca J, Zalacain R, et al. Community-acquired pneumonia in chronic obstructive pulmonary disease: a Spanish multicenter study. Am J Respir Crit Care Med 1996; 154: 1456-1461.

28 Fine MJ, Auble TE, Yealy DM, et al. A prediction rule to identify low-risk patients with community-acquired pneumonia. N Engl J Med 1997; 336: 243-250.

29 Rello J, Rodriguez A, Torres A, et al. Implications of COPD in patients admitted to the intensive care unit by community-acquired pneumonia. Eur Respir J 2006; 27: 1210-1216.

30 Salive ME, Satterfield S, Ostfeld AM, Wallace RB, Havlik RJ. Disability and cognitive impairment are risk factors for pneumonia-related mortality in older adults. Public Health Rep 1993; 108: 314-322.

31 American Thoracic Society. Guidelines for the management of adults with community-acquired pneumonia. Am J Respir Crit Care Med 2001; 163: 1730-1754.

32 Yakovlev SV, Stratchounski LS, Woods GL, et al. Ertapenem versus cefepime for initial empirical treatment of pneumonia acquired in skilled-care facilities or in hospitals outside the intensive care unit. Eur J Clin Microbiol Infect Dis 2006; 25: 633-641.

33 El Solh AA, Brewer T, Okada M, Bashir O, Gough M. Indicators of recurrent hospitalization for pneumonia in the elderly. J Am Geriatr Soc 2004; 52: 2010-2015.

34 Ruiz M, Ewig S, Marcos MA, et al. Etiology of communityacquired pneumonia: impact of age, comorbidity, and severity. Am J Respir Crit Care Med 1999; 160: 397-405.

35 Arancibia F, Ewig S, Martinez JA, et al. Antimicrobial treatment failures in patients with community-acquired pneumonia: causes and prognostic implications. Am J Respir Crit Care Med 2000; 162: 154-160.

36 Meehan TP, Fine MJ, Krumholz HM, et al. Quality of care, process, and outcomes in elderly patients with pneumonia. JAMA 1997; 278: 2080-2084.

37 Capelastegui A, Espana PP, Quintana JM, et al. Improvement of process-of-care and outcomes after implementing a guideline for the management of communityacquired pneumonia: a controlled before-and-after design study. Clin Infect Dis 2004; 39: 955-963.

38 Siegel RE, Halpern NA, Almenoff PL, Lee A, Cashin R, Greene JG. A prospective randomized study of inpatient IV antibiotics for community-acquired pneumonia. The optimal duration of therapy. Chest 1996; 110: 965-971.

39 Marrie TJ, Lau CY, Wheeler SL, Wong CJ, Vandervoort MK, Feagan BG. A controlled trial of a critical pathway for treatment of community-acquired pneumonia. CAPITAL Study Investigators. Community-Acquired Pneumonia Intervention Trial Assessing Levofloxacin. JAMA 2000; 283: 749-755.

40 Welte T, Petermann W, Schürmann D, Bauer TT, Reimnitz P, MOXIRAPID Study Group. Treatment with sequential intravenous or oral moxifloxacin was associated with faster clinical improvement than was standard therapy for hospitalized patients with communityacquired pneumonia who received initial parenteral therapy. Clin Infect Dis 2005; 41: 1697-1705.

41 Anzueto A, Niederman MS, Pearle J, et al. CommunityAcquired Pneumonia Recovery in the Elderly (CAPRIE): efficacy and safety of moxifloxacin therapy versus that of levofloxacin therapy. Clin Infect Dis 2006; 42: 73-81. 